\title{
How the Coronavirus Could Change Urban Planning
}

\section{Frank Friesecke}

Does urban planning determine humanity's chances of survival in our cities during periods of pandemics? The great importance of sustainable and health-promoting urban development is already evident from history. This chapter clarifies the connection and offers initial considerations as to whether and how the distance between humans, cars and buildings should be reappraised. The city of the future will be more digital, it will have to become more resilient to future pandemics, all of which will lead to a different planning culture. The basic functions of existence for urban society, namely living, working, basic essentials and mobility, are used to examine how the current corona crisis affects architecture and urban planning. The explanations in this chapter show that integrated urban development solutions are possible, without fundamentally calling into question the compact and dense city built on the principle of mixed use.

\subsection{Introduction}

Closed schools and shops, cordoned off children's playgrounds, deserted squares, buses and trains, orphaned pedestrian zones and virtually car-free streets: The effects of the corona crisis on urban areas are immense and can be observed worldwide. Whether it be Wuhan, New York or in the cities of Europe - the images are similar despite the great differences in architecture and urban planning.

Although the topics of hygiene and health promotion have played a role in the urban development debate since the second half of the $19^{\text {th }}$ century at the latest, due to the current pandemic it can be assumed that the planning culture will once again change fundamentally as a result of the coronavirus.

Currently more than half of humanity lives in cities or urban conurbations. This trend will continue. By 2050, it is estimated that three quarters of the world's population, i.e. around 7 billion people, will live in cities [1]. Does the Smart City, however, including tracking the movement profiles of infected city dwellers, provide the ideal image for the city of the future? Or, as a corollary of pandemics, can we anticipate a return to cities of shorter distances, in which the jobs in the "home office" or in co-working spaces are located, and where online retail has largely replaced brick-and-mortar retail premises?

The chapter deals with these and other questions. After a brief review of the urban development governing principles and concepts of the past, the intention is to present a first vision of the direction in which the city of the future could develop towards in the light of corona and other potential pandemics of the future. 


\subsection{Present: Urban Development in Corona Times}

With the spread of the coronavirus, urban planning and urban development are once again obliged to address hygiene in cities. While until recently the lack of affordable housing and, above all in Europe, the climate debate were the determining factors, the urban development policy debate is now expanding to include epidemiological issues.

Of course, the subject is not completely unknown even today. The current debate on clean air and noise reduction planning in smog-contaminated cities, as well as health promotion measures in socially disadvantaged urban districts, testify to the importance of eliminating social and health inequalities. What is new, however, is the imperative of "social distancing", i.e. measures to control infection with the aim of spatial distancing. Since it is not a matter of social isolation of individuals, the terms "spatial distancing" or "physical distancing" would be more appropriate but have not become established in the English language. In everyday life, spatial distancing means in particular keeping physical distance and avoiding physical contact (1.5 to $2 \mathrm{~m}$ distance, no hand shaking, no group formation, mask protection etc.), in the most extreme case up to restrictions on outdoor activities and contact bans.

Not only for the individual, but also from the point of view of urban planners, these restrictions are enormous, for after all the main aim in designing squares and other public and semi-public spaces is to create opportunities for social interaction. The importance of one's own living environment, local amenities, as well as parks and urban squares, is one of the key findings of recent months. Public spaces have made the pandemic more bearable. While jogging, walking or sitting on a bench, city dwellers rediscovered their surroundings, so to speak. It is likely that green spaces have never been appreciated as much as in spring 2020, when people moved outside to escape isolation at home.

In addition, the inner cities and district centres are determined by trade and consumption, by festivals, art and culture - in corona times the urban infrastructure seems strangely skeletal and meaningless. While shopping in stores poses a risk of infection, shopping at home on a smartphone or PC is completely risk-free. It is feared that numerous owner-operated shops, but also theatres, clubs, cinemas and pubs, will have disappeared after the crisis.

The current impact of the corona crisis on mobility structure has been profound, and indeed initially significantly positive. Social distancing and in particular working from home ensure less traffic, less traffic jams and fewer accidents. The proportion of people traveling to work or training places every working day has decreased significantly as a result of mobility restrictions that have been in effect almost worldwide since mid-spring 2020. In many cities, empty lanes are released for healthier forms of mobility, in particular the bicycle or e-bike, preserving individual freedom and thus becoming a solution to the many hindrances produced by the crisis.

However, there is also a major loser in the transport sector: the declining number of passengers in public transport is posing serious concerns for the future of municipal transport companies. How can the risk of infection be reduced in buses, underground and suburban trains, but also in long-distance transport? Will the car become the winner arising from the crisis after all?

\subsection{Future: The Smart, Participatory and Resilient City}

Cities are social organisms that are constantly changing. It is therefore not surprising that urban planners and architects, but also philosophers and scientists, are constantly thinking about the future of our cities. The desired spatial (and usually also social) future state is usually quickly formulated. However, a look into the past also shows how quickly a designed vision of the future can prove to be a mistake or has already been replaced by the next vision of the future.

Current developments, which in many ways represent an unprecedented watershed, require us to be cautious about coming to premature conclusions about future urban development. To call 
fundamentally into question the viability of the densely populated city in the wake of corona ignores the fact that at least Asian cities such as Hong Kong, Singapore and Tokyo have so far successfully dealt with the crisis. So density in itself is not the problem. It is about being well organized and well designed.

It cannot be denied that certain developments will accelerate significantly in the course of crisis management. The top priority is the digitalization of administrations and public institutions digital offerings and work from home have so far not yet been standard in many countries. The digital transformation enables more transparent, more efficient processes; actually having to visit authorities can be circumvented thanks to new online procedures. In the medium term, there is no way around e-Government. It should also be noted that the digital city needs an administrative apparatus that can keep up with the rapid pace of technological progress.

\subsubsection{The smart city}

Smart City solutions can improve the quality of life in existing and new urban structures, which ultimately also serve to enhance public space. A city is considered "smart" if intelligent solutions for very different areas of urban development such as infrastructure, buildings, mobility, services or security are achieved in it through the use of innovative information and communication technologies [2]. The challenges in setting up these solutions currently lie less in data collection, storage and processing than in the development of inter-faces between the individual "sub-markets" of the smart city (Smart Mobility, Smart People, Smart Economy, Smart Environment, Smart Government and Smart Living). In many European countries, corona warning apps have been developed on behalf of governments, which turn the smartphone into a warning system. Not only in China, the colour of the personalised QR Health Code scanner on the smartphone now determines whether the person should go into quarantine or is allowed to visit a reopened restaurant (red/green).

Beyond the undisputed advantages of digital solutions, the Smart City is also about personal rights issues in the area of conflict between informational self-determination and digital monitoring and control. Which personal data may be used in the event of a pandemic? A "real" Smart City would use digital technologies not only for hazard prevention or public safety, but also for less relevant public issues with urban spatial relevance.

The Smart City has not yet established itself as a model for urban development, at least not in Europe. However, the current crisis shows us more than clearly how important digital technologies are in periods of social distancing.

\subsubsection{The participatory city}

While the Smart City describes an overarching, strategically designed solution approach, the issue of citizen participation in urban development requires short-term municipal action. Ongoing planning and dialogue processes, which up to now have mainly taken place "offline" in the form of information events, future and idea workshops, but also outreach activities such as site inspections and activating surveys, must be adapted, and in many cases completely rethought.

The "digitalization of participation" [3] through websites, apps, social networks and web-based communication platforms has long been used, but habitually only in addition to analogue formats.

In these times of the corona crisis new ways of participation will have to be followed. These include online dialogues in large groups, online surveys and virtual residents' meetings. With the digital participation system DIPAS, citizens in Germany will in future be able to call up digital maps, aerial photographs, plans, 3D models and geodata and provide precisely localised feedback on planning projects. DIPAS is currently being developed by the Hamburg Ministry of Urban Development and Housing together with the State Office for Geographic Information and Surveying and the City Science Lab of the HafenCity University Hamburg (HCU). The software is open source and is to be made available as "Public Code" to other institutions for subsequent use and further development from the end of 2020.

Some European cities have already opened online participation portals, and the number of users is likely to increase significantly during corona times (see www.stuttgart-meine-stadt.de). 
In order to prevent a Hamburg resident from voting on planning processes in Stuttgart, registration is required that is tied to his or her place of residence. Inappropriate comments will be deleted immediately by an online editorial team.

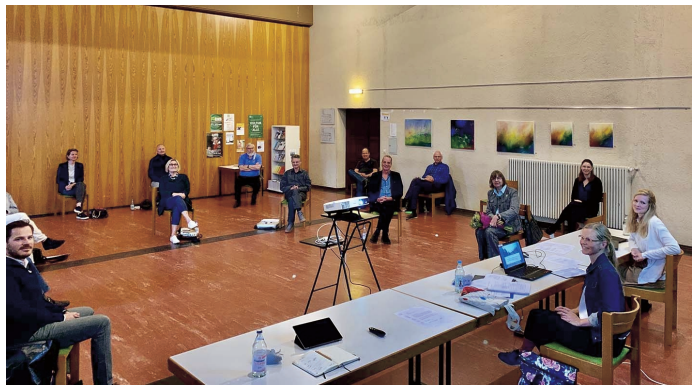

\section{FIGURE 36.1}

Participation and social distancing during Corona times, Stuttgart, Germany, Source: die STEG Stadtentwicklung GmbH

In addition to the Internet, video conferences in the exchanges between administrations and planning offices have become an everyday medium within a very short time - inevitably the question arises whether some travel routes could not have been avoided even before the crisis. It is also conceivable that consultations with owners in urban renewal areas via telephone or video could be used, but the physical surveying of the building condition of the property on-site still seems to be a continuing necessity in the future.

Despite the proven advantages of web-based interaction, it is to be hoped that the tried and tested communication channels can be used again as soon as possible after the pandemic has been overcome. Civic participation is more than just a website; good communication still always requires meeting in person.

\subsubsection{The resilient city}

From the point of view of urban decision-makers, it will be essential to review the resilience of a city or infrastructure in the future with regard to pandemic events. Adaptation concepts have so far mainly referred to natural disasters such as earthquakes, floods and heat waves $[4,5]$, but not to epidemics and, in the worst case, pandemics.

As many people live together in a relatively small area in cities, many people are affected all at once when a disaster occurs. At the same time, however, spatial concentration also creates opportunities for dealing with risks and giving better control options. The decisive factor in determining whether these advantages can be effectively utilized or whether an event turns into a disaster for many people is how these risks are handled. New York serves as an example of a metropolis that was severely affected by the coronavirus in March 2020, but was also able to contain its spread quickly through a large number of coordinated measures [6].

A good plan for urban resilience is based on a multi-dimensional approach. Holistic strategies for resilience in the event of the current corona crisis lead to a change in the planning culture, which primarily extends to the areas of living, working, shopping and moving around. The following section deals with the initial approaches that will have an impact on future urban planning and architecture. 


\subsection{Rethinking urban planning}

What can we learn from the corona crisis for the future? On the one hand, the current pandemic is challenging the resilience of our society and especially our cities. On the other hand, coping with it will trigger processes of change that offer a wide range of opportunities for sustainable urban development.

Unintentionally, the corona crisis is becoming a kind of real-life laboratory for the city of the future. So what can cities learn from the lockdown? What structures for the resilient city after corona are already emerging?

Based on the essential functions of existence for urban society, namely living, working, basic essentials and mobility, the following outlines the changes resulting from the current crisis and which solutions urban planning and architecture can respond with.

\subsubsection{Housing}

As an elementary basic need, housing is one of the central urban functions. However, the demands on housing are very heterogeneous and vary greatly according to region, social affiliation and individual preferences. Housing needs depend on demographic, technical, social and economic parameters that are volatile over time and can only be controlled to a limited extent.

Despite these differences, it has become clear, especially in the current crisis, that the single-family home in the suburbs or in the countryside, which has been critically judged for decades, was a relatively pleasant place to spend lockdown: stable neighbourhoods, long-standing and personal shopping relationships, private garden areas and generous floor plans for one's own family and home office are extremely helpful to this end. Owners were also often at an advantage over tenants because they were able to generate added value through repairs and improvements during the period of short-time work.

However, this is not the only reason why the demand for housing will increase even more than expected in the future: thanks to digital technologies, many companies have made it possible to work from home, and many working people may not even return to their open-plan offices. Yet, there is still a lack of flexible floor plans at home that allow living and working in a home office and that provide sufficient privacy and retreat.

For architects, this means building apartments in such a way that different forms of living coexist in one house. So small apartments, large apartments, and that there is perhaps one dedicated apartment for guests set in every apartment building. That there are work or common rooms in the house, which can be shared not only in times of crisis. It is about establishing forms of living that bring living and working closer together again.

For urban planners, this means making public spaces that were often neglected in the past more attractive when planning new quarters, but also in existing areas. If the expensive city apartment is small, the living environment becomes even more important - public green spaces and places within walking distance, short distances to shopping and to medical practices. More open spaces on which urban agriculture is practiced can also be a solution along the lines of the urban gardening movement. The demand for allotment gardens, at least in Germany, has more than doubled compared to the previous year. The waiting time for one of the almost 1 million allotments in certain regions has been several years [7].

In principle, the city has everything to survive quarantine periods - if it is planned consistently. What is new is that there should be an overview of the necessary separation distance areas, especially in public facilities, shops and restaurants.

\subsubsection{Work}

As can be seen from the previous section, the urban functions of living and working are mutually dependent and cannot be substituted for a functioning city. A return to the functionally segregated city is no longer appropriate in times of climate change anyway. 
Overall, it can be assumed that corona will have the most lasting impact on the world of work. Working from home will become a permanent and steadily growing part of the working world. As a result, oversized office buildings and even more space will become available in the city. The role of the central office could be taken over by the study in the (larger) apartment, but also by decentralised offices close to the apartment. In their own neighbourhood or district, between grocery stores, hairdressers, snack bars and cafe's, people could work in co-working spaces and thus avoid commuting to work.

Structural changes will not be avoided for the hitherto open plan office space. An obvious concept is the return to the so-called Cubicles. This technique of dividing an open-plan office into smaller personal areas, which had been in use since the 1970s, had actually seemed to have run its course, but is now experiencing something of a renaissance.

On the other hand, in the medium term it is necessary to convert offices in the city centres that are no longer needed. Demand has been great for centrally located apartments not only since corona, yet in many places the (still) very high prices for condominiums and the high rent level prevent affordable living in the city. This could change in the future, since in addition to office properties, retail properties are even more threatened by non-occupancy. Living and possibly also working in a previous office premises converted into an apartment - or a former ground floor shop - this too could represent a future for the city centre.

\subsubsection{Retail business}

One of the greatest threats to the inner cities has already been identified. The gradual creeping disappearance of the classic activity of going shopping, at least in the city, has been now greatly accelerated by the pandemic.

The competition against brick-and-mortar retail is already clear: Online business is the great beneficiary of the crisis. When non-food stores in the inner cities had to close, many consumers switched to existing online offerings. Although not all industries benefited equally from the boom in online retailing, online giant Amazon alone was able to increase its sales by 26 percent in the first quarter of 2020 compared to the previous year [8].

In order to prevent city and town centres from becoming deserted, one of the aims will be to designate smaller core zones in which trade has priority over other uses. Outside these areas, vacant buildings will be given a new use, either by conversion or by demolition and new construction. In growing cities, it will be primarily residential use that will replace the previous retail use.

In many cases, however, quick, creative solutions are also needed to mitigate the crisis: In Berlin, Boston, Paris and elsewhere, "pop-up street restaurants" have been approved relatively easily restaurateurs are allowed to use adjacent parking spaces as extended outdoor terraces.

In order to prevent a final decline of the inner city as a location for basic essentials, it will be important to actively shape the structural change. The affected owners must act jointly in the same direction, and this requires above all new forms of cooperation. Municipal authorities will have to play a leading role in the renewal process, but private initiatives can also make their contribution to strengthening the inner cities (e.g. business improvement districts). Much of this will only work in small-scale - property by property, street by street.

For urban planners, the change in consumer behaviour also impacts the outskirts of cities: If the currently forced change in shopping behaviour continues to move in the direction of online trading, this will be accompanied by an increase in logistics centres, warehouses and other large-scale infrastructures. For a long-term and resilient urban development, the high-quality design of these new commercial megastructures is absolutely essential.

In order to avoid these area-intensive developments, considerations regarding more compact spatial production structures should also be realized in urban areas. One approach could be the "urban factory" concept, which integrates industrial production into the urban context by means of a city-factory interface [9].

In the light of current events, the overall question is whether certain services should be decentralised, not only in the health sector but also in the provision of care in general. This in turn has implications for urban planning and architecture. 


\subsubsection{Transport and mobility}

Does the pandemic also serve as an accelerator for new urban transport concepts? The spread of the coronavirus and the resulting initial restrictions led to a forced, unprecedented, breathing space for traffic. People have reduced their everyday mobility to a minimum and shifted it significantly: The proportion of walking and cycling has increased, while that of local public transport has fallen dramatically [10].

During the crisis it has become clear that urban transport areas are not divided up according to demand. In the current situation, at least 1.5 meters distance from other people in public spaces should be kept to minimize the risk of infection. Narrow or non-existent bicycle lanes and sidewalk parking make it difficult to comply with the prescribed distance rules.

Many cities have reacted to the changed mobility behaviour with appropriate measures in the short term. In Brussels, the city centre (Pentagon Zone) is being converted to an extensive pedestrian and cycling zone, Paris is investing 300 million euros in new (pop-up) cycling infrastructure to connect the entire city and prepare it for increased cycling after the lockdown. Oakland in California has developed the concept of slow streets, where 10 percent of all roads are closed to through traffic. Already today, one in two households in the inner city of Berlin no longer owns a car, simply because they no longer need one [11].

Is the car-friendly city a thing of the past? Against this background, the size of a city makes a significant difference. The smaller the city, the higher the proportion of car journeys, the longer the distances travelled and the lower the proportion of public transport. Even if mobility after corona will not be different everywhere, the same is true for small towns: Urbanity is created primarily where people get around on foot or by bicycle, and not by a solid line of cars meandering through the city centres, district centres or town centres.

In addition to the newly forming traffic flows, it is digitalization and smart technologies that are leading to more efficient traffic control. This applies in particular to motorised private transport, which is one of the great benefiters of the crisis. An infrastructure that thinks ahead helps to steer traffic flows in such a way that traffic jams do not occur in the first place. Finding a parking space can soon be a thing of the past if networked vehicles know where the next gap in the parked cars will be.

A great many people are already traveling intermodally, so they use several means of transport on their journeys. IT applications and apps on smartphones can link data on the location of vehicles and people, tariffs and route information and both create new, networked transport offers and facilitate access to them.

Is the corona crisis a catalyst for changing transport behaviour? Will the old mobility patterns return afterwards? The everyday behaviour of each individual will depend on whether transport and urban planners succeed in making public space attractive for health-promoting forms of mobility.

\subsection{Conclusion}

How pandemic based must future urban planning be? In his major work "The Man Without Qualities", first published in 1930, Robert Musil came to the following observation: "Modern man is born in the clinic and dies in the clinic: therefore he should also be living like he is in a clinic" [12].

Even if the requirements of leading architects at the time of the Neues Bauen are judged differently nowadays, the question of integrating hygiene regulations, larger spacing and changed floor plans for apartments, retail, offices and public facilities into urban development is still being raised. The illustrations in this chapter show that (urban) construction and architectural solutions are possible in this respect, without fundamentally calling into question the compact and dense city built on the principle of mixed use.

With regard to the changed trading and transport behaviour in corona times, only the future will show whether there will be a reversion to old consumption and mobility patterns, or whether 
there will be a sustainable and lasting change. Conversion strategies for empty properties require ideas to make commercial and district centres more attractive again, but also eco-nomic stimulus programmes are needed in order to be able to finance the necessary measures in the foreseeable slump in municipal finances.

One conclusion is thus obvious: The far-reaching changes in all essential functions of existence for the urban society, i.e. living, working, basic essentials and mobility, do not only mean loss or deprivation, but above all an opportunity for future urban and transport planning. Urban development and spatial planning do not have to be reinvented, but what is required is an urban experimentalism in the cities, combined with municipal decision-making power and civil society commitment [13].

For a successful integration of adaptation measures in urban planning and development, a societal process is required that can only succeed if it is anchored beyond politics and administrative spheres involving private sector stakeholders (including retail, housing industry) and involving residents too. There is no doubt that digitalization and new technologies will play a significant role in this process.

\section{References}

[1] United Nations, Population Division of the Department of Economic and Social Affairs. World Population Prospects 2019. 2019.

[2] Gassmann, O., Böhm, J., Palmié, M. Smart Cities: Introducing Digital Innovation to Cities. Melbourne: Emerald Publishing Limited, 2019.

[3] Selle, K. Partizipation 8.0 - Bürgerinnen und Bürger in Prozessen der Stadtentwicklung. In: Informationen zur Raumentwicklung, Heft 6/2017. page 12ff, 2017.

[4] BBSR Bundesinstitut für Bau-, Stadt und Raumforschung (Hrsg.). Stresstest Stadt - wie resilient sind unsere Städte? Unsicherheiten der Stadtentwicklung identifizieren, analysieren und bewerten. 2018.

[5] Vale, L.W. The Resilient City: How Modern Cities Recover from Disaster. Oxford University Press, 2005.

[6] New York State Government. NY Forward - A Guide to Reopening New York \& Building Back Better. URL https://www.governor.ny.gov/sites/governor.ny.gov/files/atoms/files/NYForwardReopeningGuide.pdf. (Accessed: 30.06.2020).

[7] Süddeutsche Zeitung vom 1.6.2020. Corona-Beschränkungen sorgen für "Run auf Kleingärten". URL https://www.sueddeutsche.de/leben/freizeit-corona-beschraenkungen-sorgen-fuer-run-auf-kleingaertendpa.urn-newsml-dpa-com-20090101-200601-99-260144.

[8] Weise, K. Amazon Sells More, but Warns of Much Higher Costs Ahead, in: The New York Times from April 30, 2020. URL https://www.nytimes.com/2020/04/30/technology/amazon-stock-earnings-report.html. (Accessed: 30.06.2020).

[9] Bucherer, M., Clausen, U., Herrmann, C. et al. Urban Factory - Entwicklung ressourceneffizienter Fabriken in der Stadt. Abschlussbericht. Braunschweig, 2019. URL https://publikationsserver.tu-braunschweig.de/ receive/dbbs_mods_00066906.

[10] Meyer, H. Corona und Mobilität: Mehr Homeoffice, weniger Berufsverkehr. Onlineartikel vom 08.04.2020 URL https://www.adac.de/verkehr/standpunkte-studien/mobilitaets-trends/corona-mobilitaet/. (Accessed: $22.04 .2020)$.

[11] Jacobs, S., Keilani, F., Betschka, J., Seeling, B., Van Bebber, W. "Meinen eigenen Wagen habe ich lange verkauft", in: Der Tagesspiegel vom 5.1.2020. URL https://www.tagesspiegel.de/berlin/autofreieinnenstadt-meinen-eigenen-wagen-habe-ich-lange-verkauft/25388382.html. (Accessed: 1.07.2020).

[12] Musil, R. Der Mann ohne Eigenschaften, Band 1: Erstes und Zweites Buch. Hamburg: Rowohlt Verlag., 1971.

[13] Roesler, S. Epidemiologie und Stadtplanung haben eine gemeinsame Geschichte und auch Zukunft. In: Neue Zürcher Zeitung vom 03.04.2020. URL https://www.nzz.ch/feuilleton/epidemiologie-und-stadtplanunghaben-eine-gemeinsame-geschichte-und-auch-zukunft-ld.1549809. (Accessed: 30.06.2020). 